Revista Destaques Acadêmicos, Lajeado, v. 12, n. 3, 2020. ISSN 2176-3070

DOI: http://dx.doi.org/10.22410/issn.2176-3070.v12i3a2020.2378

http://www.univates.br/revistas

\title{
PROJETO PILOTO DE ANÁLISES DE SOLOS DE UMA PROPRIEDADE RURAL DO VALE DO TAQUARI
}

\author{
Cibel de Fátima de Oliveira da Silva ${ }^{1}$, Amanda Luisa Stroher ${ }^{2}$, \\ Juliana de Araujo ${ }^{3}$, Claudete Rempel ${ }^{4}$, Mônica Jachetti Maciel ${ }^{5}$
}

Resumo: O solo é o recurso natural responsável por estimular o desenvolvimento das espécies vegetais e também por ser um dos meios de sobrevivência da humanidade, que se utiliza de métodos naturais e artificiais para a melhoria da produção de alimentos. Assim, o presente estudo teve como objetivo testar metodologias de análise de solo para a implementação no grupo de pesquisa. Realizou-se a coleta de solos de três diferentes manejos: área com cultivos temporários, de floresta nativa e de cultivo de pasto. A coleta foi realizada em um único momento (março de 2017). Em cada manejo, os solos foram amostrados em cinco pontos diferentes (nos cantos e nos centros de um quadrante de 1 $\mathrm{m}^{2}$ ) em uma profundidade de $5 \mathrm{~cm}$. Foram realizadas análises de umidade, $\mathrm{pH}$, metais $(\mathrm{K}, \mathrm{Zn}, \mathrm{Cu}, \mathrm{Mn}, \mathrm{Al}, \mathrm{Ca}, \mathrm{Mg})$ e não-metais (P, S, B, N), estimativa da acidez potencial, análises granulométricas (areia, silte e argila), matéria-orgânica, respiração basal e biomassa microbiana. Para a determinação de fungos, fez-se o uso da metodologia de diluição decimal utilizando o ágar Sabouraud Dextrose e posterior identificação micro/ macroscópica. Em relação aos resultados das análises físico-químicas e biológicas obtidos e a comparação desses dados com os demais estudos, pode-se perceber que as metodologias testadas podem ser utilizadas e implementadas no grupo de pesquisa.

Palavras-chave: Qualidade. Fungos. Manejo do solo. Diversidade biológica.

1 Acadêmica do Curso de Ciências Biológicas, da Universidade do Vale do Taquari- Univates, Lajeado/RS, Brasil.

2 Acadêmica do Curso de Biomedicina, da Universidade do Vale do Taquari- Univates, Lajeado/ RS, Brasil.

3 Acadêmica do Curso de Engenharia Química, da Universidade do Vale do Taquari- Univates, Lajeado/RS, Brasil.

4 Bióloga, professora doutora do Centro de Ciências Médicas (CCM), do Programa de PósGraduação em Ambiente e Desenvolvimento (PPGAD) e do Programa de Pós-Graduação em Sistemas Ambientais Sustentáveis (PPGSAS), da Universidade do Vale do Taquari- Univates, Lajeado/RS, Brasil.

5 Bióloga, professora doutora do Centro de Ciências Biológicas e da Saúde (CCBS) e do Programa de Pós-Graduação em Sistemas Ambientais Sustentáveis (PPGSAS), da Universidade do Vale do Taquari- Univates, Lajeado/RS, Brasil. 


\section{INTRODUÇÃO}

O Vale do Taquari está situado na região central do Rio Grande do Sul, sendo formado por 36 municípios, totalizando uma área de $4.826,4 \mathrm{~km}^{2}$, o que representa cerca de 1,71\% da área total do Estado (FEIX, 2016). Segundo dados da Fundação de Economia e Estatística (FEE, 2015), em 2015, a região contava com 352.943 habitantes, correspondendo a 3,11\% da população gaúcha.

Em relação aos aspectos econômicos, predominam nessa região a agricultura familiar que produz milho, soja, fumo e diversos outros produtos de subsistência das famílias, além das atividades industriais, comerciais e serviços. No setor pecuarista, muitos produtores rurais se especializaram na criação de gado leiteiro, suínos e a avicultura de corte e postura, porém a predominância é de gado leiteiro, o qual gera uma grande produção e renda, sendo uma importante fonte econômica para as famílias (FEIX, 2016).

No ano de 2016 o Brasil produziu cerca de 33,62 bilhões de litros de leite, sendo que a região Sul foi responsável por cerca de $37,0 \%$ deste total (IBGE, 2017). A produção leiteira na região constituiu-se como uma atividade economicamente favorável pois gerou renda aos agricultores e melhorou o desenvolvimento regional (JUNG; JUNIOR, 2017).

O solo possui fundamental importância na criação de condições adequadas para o fortalecimento da produção agrícola e da criação animal. É a partir dele que ocorre a sustentação da vida vegetal e animal (SETZER, 1941). O solo pode ser classificado pelos mais variados componentes químicos, físicos e biológicos (EMBRAPA, 2006), apresentando características próprias, tais como a textura, tonalidade, fertilidade e também pela quantidade de minerais e organismos que nele podem ser encontrados (COELHO et al., 2013). Muitas vezes, a intervenção humana acaba modificando os componentes do solo (EMBRAPA, 2006).

É por meio dessas características dos solos que se pode determinar os mais variados tipos de vegetação, plantação e diversidade de plantas no ambiente. Os solos são originados da decomposição das rochas, assim como tem influência nos organismos vivos, como os fungos, líquens, bactérias (COELHO et al., 2013). Os fatores que podem ocasionar alterações no solo, e até atributos promissores ou indesejados, estão relacionados diretamente com o meio biológico e aspectos físico-químicos que auxiliam e apresentam condições de melhoramento no desenvolvimento das plantas e demais vegetações (SILVA et al., 2009).

Segundo Moreira e Siqueira (2006), existem diversos elementos que afetam os organismos do solo e podem influencias suas populações, como o tipo de solo, a vegetação e as condições climáticas. Dessa forma, grandes variações nas comunidades microbianas podem ser encontradas entre ecossistemas distintos em uma mesma região ou em regiões geográficas diferentes. Além 
disso, as variabilidades dos micro-habitats permitem a existência de organismos com características bem diversas.

As relações simbióticas entre fungos e plantas auxiliam a absorção de nutrientes do solo e água por meio do aumento da superfície de contato. São essenciais para ingestão de elementos, especialmente aqueles não muito móveis, como o fósforo. Desta maneira, a comunidade micológica do terreno interfere na vegetação e aqueles que dela dependem (TORTORA; FUNKE; CASE, 2016).

A pastagem é a principal forma de alimentação na pecuária no Brasil, sendo suas características nutricionais e físicas importantes componentes de qualidade para a nutrição animal. Especialmente nos períodos de seca, no qual ocorre o chamado diferimento da pastagem, acontece a diminuição de matéria para a nutrição dos bovinos. À vista disso, as propriedades do solo e sua vegetação devem ser mantidas para garantir a correta nutrição do rebanho (ALVES et al., 2014).

As análises físico-químicas são importantes para determinar os teores dos elementos encontrados nas amostras e identificar sua relação com o ambiente. Segundo Santos et al. (2009), a absorção de fósforo pelo sistema solo-planta-animal encontra-se fortemente relacionada com o teor de outros elementos como alumínio, manganês, ferro e cálcio, e estes, com o $\mathrm{pH}$ do solo. Em seus estudos avaliativos, concluíram que o tipo de solo e o clima da região influenciam nessas características químicas e físicas. $O$ nitrogênio é um elemento essencial para o crescimento da vegetação em todas as épocas do ano, devendo estar presente em grandes quantidades (ALVES et al., 2014).

A granulometria determina as partículas encontradas no solo (areia, silte e argila) e suas quantidades. Sua definição e avaliação é importante, pois possuem relação com a quantidade de água e umidade, permeabilidade, absorção de nutrientes e textura do solo (KITAMURA, 2007).

Frente ao exposto, o presente estudo teve como objetivo testar metodologias de análise de solo para a implementação no grupo de pesquisa.

\section{MATERIAL E MÉTODOS}

\section{Local de coleta e caracterização das áreas de estudo}

As coletas das amostras dos solos foram realizadas em uma propriedade rural localizada no interior do município de Arroio do Meio, situado no Vale do Taquari, Rio Grande do Sul, conforme ilustra a Figura 1. Foram amostrados três pontos de coletas: solo de plantação agrícola temporária $\left(29^{\circ} 20^{\prime} 32^{\prime \prime} \mathrm{S} 52^{\circ}\right.$ $\left.1^{\prime} \mathrm{W}\right)$, solo de floresta nativa $\left(29^{\circ} 20^{\prime} 41^{\prime \prime} \mathrm{S}, 52^{\circ} 1^{\prime} \mathrm{W}\right)$ e solo para a plantação de pastagem $\left(29^{\circ} 20^{\prime} 38^{\prime \prime} \mathrm{S}, 52^{\circ} 1^{\prime} \mathrm{W}\right)$. 
Figura 1- Imagem de satélite da propriedade rural onde foram realizadas as coletas.

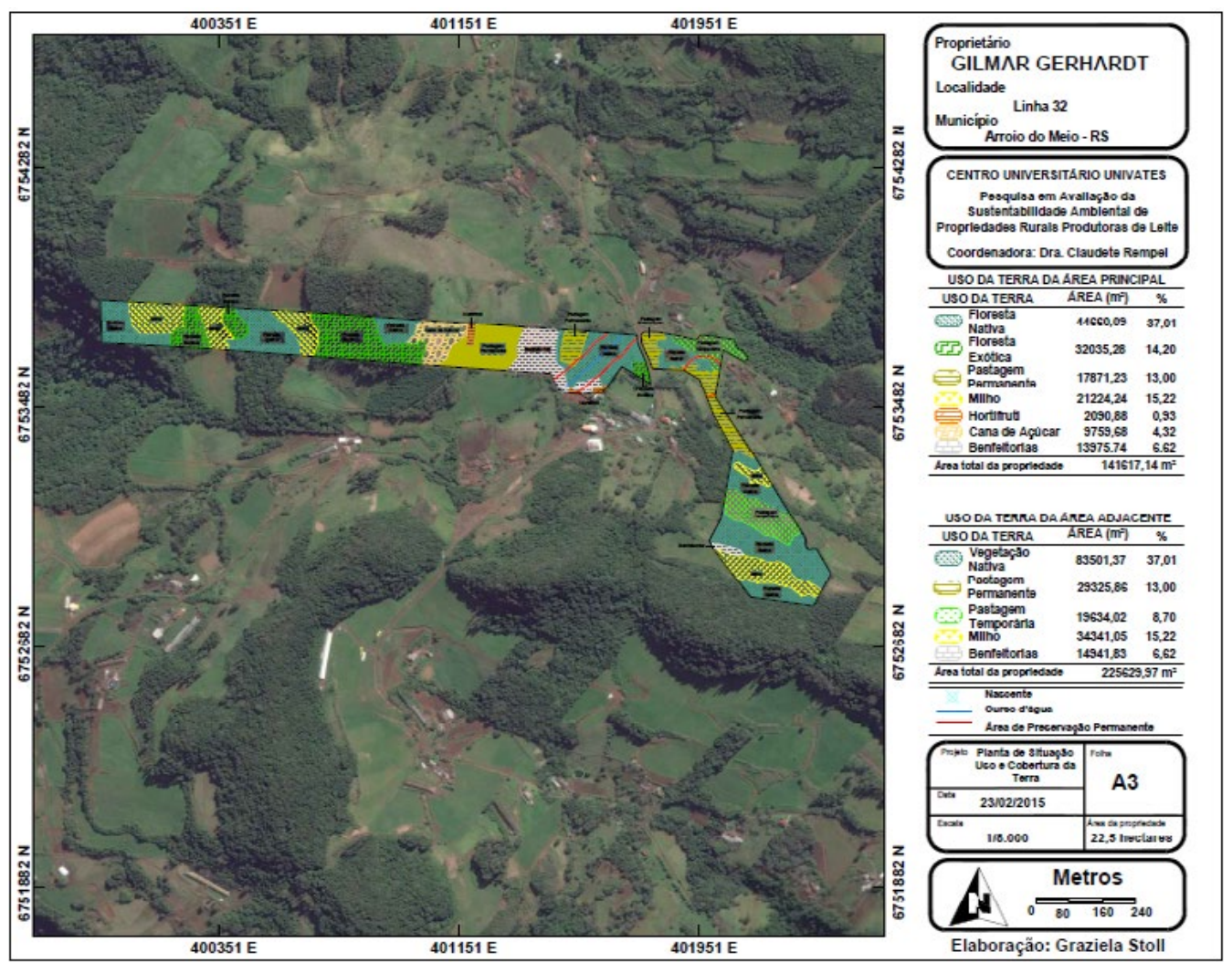

Fonte: Autoras (2019).

\section{Coleta}

Para minimizar os efeitos na comunidade microbiana em cada local, as amostragens foram realizadas em um único dia, no mês de março de 2017. Após a remoção de parte das sujidades superficiais, as massas de solo foram coletadas ao acaso, com o auxílio de um trado modificado. As amostras foram coletadas em seis pontos diferentes, amostrando-se os cantos e o centro do quadrante de $1 \mathrm{~m}^{3}$ sendo a dimensão desta amostragem de $10 \mathrm{~cm}$ de diâmetro e $5 \mathrm{~cm}$ de profundidade. As amostras dos solos coletados foram armazenadas em um balde plástico previamente desinfetado com álcool $70^{\circ} \mathrm{GL}$. Após esta coleta, as amostras foram misturadas, homogeneizadas e transferidas para um saco de stomacher estéril, colocadas em uma caixa de isopor contendo gelo e transportadas até a Universidade do Vale do Taquari - Univates, no laboratório de Microbiologia Didático. Em seguida as amostras permaneceram por 24 horas em uma estufa bacteriológica $\left(25^{\circ} \mathrm{C}\right)$. 


\section{Análises físico-químicas}

As análises de umidade e $\mathrm{pH}$ foram realizadas no Laboratório de Química, da Universidade do Vale do Taquari - Univates. Na análise de determinação de umidade (EMBRAPA, 1997), pesou-se cerca de $4 \mathrm{~g}$ de amostra de solo em cápsulas de porcelana secas a $105^{\circ} \mathrm{C}$ e secou-se a amostra em estufa também a $105^{\circ} \mathrm{C}$, conferindo-se os valores da pesagem de 2 em 2 horas até a estabilização. $\mathrm{O}$ cálculo foi realizado da seguinte maneira: $\mathrm{U}=100 \times(\mathrm{N} / \mathrm{P})$, onde $\mathrm{U}$ representa a umidade da amostra, $\mathrm{N}$ o número em gramas de umidade e $\mathrm{P}$ o número de gramas da amostra. O número de gramas de umidade $(\mathrm{N})$ foi calculado subtraindo-se o peso inicial do peso final da amostra ( $\mathrm{N}=\mathrm{Pi}-\mathrm{Pf})$. Para a análise de $\mathrm{pH}$, fez-se o uso de $\mathrm{pHmetro}\left(\right.$ Digimed $\left.{ }^{\circledR}\right)$, segundo a metodologia da EMBRAPA (1997).

As amostras de solos foram encaminhadas para a Central Analítica da Universidade de Santa Cruz do Sul - UNISC/RS e as seguintes análises foram realizadas: determinação de areia, silte, argila, estimativa da acidez potencial (método pH - SMP), quantificação de metais (potássio, zinco, cobre, magnésio, alumínio, cálcio e manganês) e não-metais (fósforo, enxofre, boro e nitrogênio) e de matéria orgânica.

\section{Análises biológicas}

A biomassa microbiana do solo foi determinada pelo método descrito por Vance, Brookes e Jenkinson (1987), com amostras radiadas e irradiadas, utilizando o forno de micro-ondas $\left(2.450 \mathrm{MHz}\right.$, Panasonic ${ }^{\circledR}$, Modelo EM 9003B). Para cada área amostrada durante a coleta foi realizada uma análise de biomassa microbiana.

A respiração basal do solo foi determinada pela quantificação do dióxido de carbono $\left(\mathrm{CO}_{2}\right)$ liberado no processo de respiração microbiana, conforme metodologia proposta por Stotzky (1965). Foram realizadas triplicatas para cada uma das três áreas amostradas inicialmente, totalizando nove análises. Ao final foi calculada a média entre elas e os resultados, tabelados. A avaliação do quociente microbiano $(q \mathrm{CO} 2)$ foi determinada conforme Anderson e Domsch (1990), sendo obtido a partir da relação de biomassa microbiana (BM) e respiração basal (RB).

\section{Análises micológicas: isolamento, quantificação e identificação dos fungos}

Para o isolamento dos fungos, foi utilizada a técnica da diluição decimal seriada, na qual pesou-se $10 \mathrm{~g}$ de solo, e homogeneizou-se com $90 \mathrm{~mL}$ de peptona salina 0,1\%, para posterior diluição. Em seguida, as amostras foram plaqueadas em placas de Petri contendo ágar Sabouraud Dextrose acidificado (Oxoid). De cada diluição foi retirada uma alíquota de $0,1 \mathrm{~mL}$ e realizada a inoculação na superfície do meio. As placas foram incubadas a $25^{\circ} \mathrm{C}$, durante 5 dias em estufa com umidade controlada (BDO). Após esse período, realizou- 
se a contagem dos fungos e os resultados foram expressos em Unidades Formadoras de Colônias por grama de solo (UFC/g de solo).

Após a contagem das colônias presentes nas placas, fez-se o seu reisolamento pelo uso da técnica de esgotamento por estrias. Em seguida, as placas foram incubadas a $25^{\circ} \mathrm{C}$, durante 5 dias e então montou-se os microcultivos dos fungos, realizando-se registros fotográficos para posterior identificação. A identificação foi baseada nas características macroscópicas e microscópicas dos isolados. Para o estudo macroscópico observou-se a superfície e o reverso das colônias, quanto ao diâmetro, cor dos conídios e micélios, textura, presença de exudados e pigmentos solúveis. Para a identificação dos gêneros, fez-se o uso de literaturas específicas, utilizando-se chaves como as dos autores Domsch e Walter (2007), Ellis (1971), Pitt e Hocking (2009).

\section{Análise dos dados}

A existência de associação entre os parâmetros do solo foi avaliada pelo Teste de Correlação Linear de Pearson, com nível de significância de 5\%. As correlações entre as médias foram efetuadas com uso do programa BioEstat versão 5.3. A correlação foi aplicada entre os variáveis solos de diferentes usos e análises físico-químicas (umidade, $\mathrm{pH}$, índice $\mathrm{pH}$ SMP; quantificação de metais; quantificação de não-metais), análises biológicas (biomassa microbiana, respiração basal, quociente microbiano e gêneros de fungos. Também foi avaliada a correlação entre a granulometria e gêneros de fungos. Não existem valores que servem de parâmetros para as análises realizadas.

\section{RESULTADOS E DISCUSSÃO}

No solo da plantação agrícola temporária havia cultivo de milho que se encontrava em fase de crescimento. No solo da floresta nativa, o ambiente estava bastante úmido, com a presença de vegetação extensa e com diversas espécies de plantas. Já o solo para a produção de pastagem era um local cercado, não permitindo o acesso do gado e sem árvores, nesta área se cultivava o pasto que posteriormente seria dado aos animais.

Um fator de notável importância é a estrutura do solo. Esta é definida por três partículas consideradas primárias, como a areia, o silte e a argila. A argila é a principal partícula, por ser a mais importante na estabilidade de agregados. A interação desses agregados se dá pelo manejo do solo, fatores ambientais, composição mineral, textura e atividade microbiana. As diferentes texturas compostas por estas partículas podem influenciar positiva ou negativamente as taxas de matéria orgânica, umidade, nutrientes e minerais, e estas afetam diretamente o desenvolvimento da comunidade microbiana do local (BRADY, 1989). Na Tabela 1, apresentam-se os resultados das análises de granulometria (areia, silte e argila) e matéria-orgânica dos três tipos de solo analisados. 
Tabela 1- Resultados das análises de granulometria (\%) e matéria-orgânica (M.O.) (\%).

\begin{tabular}{l|c|c|c|c}
\hline Tipo de Solo & Areia (\%) & Silte (\%) & Argila (\%) & M.O. (\%) \\
\hline Floresta Nativa & 16 & $\mathbf{5 2}$ & 30 & 8,3 \\
\hline $\begin{array}{l}\text { Produção de } \\
\text { Pastagem }\end{array}$ & 24 & $\mathbf{5 0}$ & 24 & 5,6 \\
\hline $\begin{array}{l}\text { Plantação Agrícola } \\
\text { Temporária }\end{array}$ & 17 & $\mathbf{4 3}$ & 39 & 2,9 \\
\hline
\end{tabular}

Fonte: Autoras (2019).

Segundo Silva et al. (2006), os diferentes sistemas de usos de solos interferem nas condições de argila e suas propriedades. Um solo com sistemas de irrigação aumenta as quantidades de argila, pois a mesma fica dispersa em água, podendo reduzir a estabilidade dos agregados. A quantidade de argila representada na Tabela 1, apresentou resultado maior no solo de plantação. Este solo recebe diferentes tipos de manejos durante o ano, fazendo com que interferências da adubação, irrigação e drenagens influenciem na estrutura de seus agregados.

Em relação a matéria-orgânica presente no solo, esta pode sofrer alterações por meio dos diversos tipos de manejos agrícolas, fazendo com que os solos se tornem mais sensíveis e mais fracos em relação a sua estrutura física e biológica, causando inúmeras transformações no seu meio. A matériaorgânica pode apresentar diversas composições que se originam de processos decorrentes da decomposição do material animal e vegetal depositado no solo (LONGO; ESPÍNDOLA, 2000).

Avaliando-se os resultados de matéria-orgânica deste estudo, percebese que há uma quantidade maior no solo de floresta nativa em relação ao demais. Isso provavelmente ocorre porque nos sistemas naturais existe um equilíbrio dinâmico, ou seja, os ciclos biogeoquímicos estão mantendo a ciclagem e a disponibilidade dos nutrientes (TORTORA; FUNKE; CASE, 2016). Em solos nos quais não houveram ocorrências de desmatamento, tampouco o manejo inadequado da terra, tem-se maior quantidade de carbono presente, aumentando a matéria orgânica. Já nos sistemas agropecuários intensivos os nutrientes são retirados do solo (SILVA; POLLI, 2020) em função da má gestão. Além disso, são áreas com perdas no estoque de oxigenação, diminuindo, consequentemente, a quantidade de matéria-orgânica (MARCHIORI JÚNIOR; MELO, 2000).

Microrganismos em solos atuam na decomposição da matéria-orgânica, possuindo um importante papel no ciclo dos nutrientes e fazendo com que estejam disponíveis no solo. Dessa forma, a biomassa microbiana representa um reservatório de nutrientes para as plantas (GRISI; GRAY, 1986). Esta 
biomassa está diretamente relacionada a matéria-orgânica do solo e possui funcionalidades que permitem modificações no solo (ANDRADE et al., 1995). pH SMP.

Na Tabela 2 podem ser encontrados os dados de umidade, $\mathrm{pH}$ e índice

Tabela 2- Resultados das análises de umidade (\%), pH e índice pH SMP.

\begin{tabular}{l|c|c|c}
\hline \multicolumn{1}{c|}{ Tipo de Solo } & Umidade (\%) & pH & Índice pH SMP \\
\hline Floresta Nativa & $31,8772 \pm 0,6054$ & $5,5 \pm 0,2160$ & 6,4 \\
\hline Produção de Pastagem & $17,8333 \pm 0,0893$ & $5,6 \pm 0,0500$ & 6,1 \\
\hline $\begin{array}{l}\text { Plantação Agrícola } \\
\text { Temporária }\end{array}$ & $15,1240 \pm 0,0158$ & $5,6 \pm 0,0816$ & 5,5 \\
\hline
\end{tabular}

Fonte: Autoras (2019).

Quanto a análise de umidade, o solo de plantação agrícola temporária e o de produção de pastagem obtiveram resultados próximos, sendo muito menores em relação a área de floresta nativa. Isto se deve ao fato de que solos com menor cobertura vegetal ficam expostos às radiações solares e sofrem mais a ação dos ventos, apresentando uma redução na taxa de umidade (ALMEIDA et al., 2009).

Para o solo de floresta nativa, o resultado foi mais elevado, pois estas florestas apresentam em sua própria composição uma quantidade maior de matéria-orgânica, que implica diretamente em um aumento da umidade do solo. Isto ocorre, pois, o tipo de matéria-orgânica presente neste solo favorece a agregação de partículas e minerais, formando um solo mais uniforme e menos poroso, que impede o escoamento da água e aumenta sua umidade (BRADY; WEIL, 2012; PES; ARENHARDT, 2015).

Quanto ao $\mathrm{pH}$, a maioria dos solos possuem $\mathrm{pH}$ entre 4,0 e $8,5 \mathrm{em}$ climas mais úmidos. A incidência de chuvas ácidas e fertilização pesada podem contribuir para que o $\mathrm{pH}$ seja baixo (MOREIRA; SIQUEIRA, 2006). Para este estudo, os resultados de $\mathrm{pH}$ estiveram entre 5,5 e 5,6, e o índice $\mathrm{pH}$ SMP com valores entre 5,5 e 6,4 .

Fungos são mais adaptáveis a valores de $\mathrm{pH}$ menores que 5,0, e bactérias a valores de $\mathrm{pH}$ entre 6,0 e 8,0. A menor incidência de fungos em solos com esta faixa de $\mathrm{pH}$ mais favorável às bactérias, ocorre, possivelmente, pelo fato de bactérias serem competidoras mais eficientes, reduzindo a comunidade fúngica no local (MOREIRA; SIQUEIRA, 2006).

Valores de pH entre 8,2 e 8,6 podem indicar a ocorrência de cálcio e magnésio livres, e tornarem baixas as ocorrências dos elementos $\mathrm{P}$ (fósforo), Mn (manganês), Zn (zinco) e Cu (cobre) (KIEHL, 1979). O presente trabalho indica resultados de $\mathrm{pH}$ abaixo de 6, podendo significar a diminuição de alguns 
nutrientes e minerais, porém, segundo Moreira e Siqueira (2006), os fungos se adaptam melhor a estes ambientes.

Na Tabela 3 estão apresentados os resultados das análises físico-químicas dos metais (K, Zn, Cu, Mn, $\mathrm{Al}, \mathrm{Ca}, \mathrm{Mg}$ ) e na Tabela 4, os não-metais (P, S, B), para os três tipos de solos. De acordo com Moreira e Siqueira (2006) os metais do solo são provenientes de fontes antropogênicas (pesticidas, fertilizantes, rejeitos industriais, mineralização, queima de combustíveis, ...) e da intemperização dos materiais de origem. Os elementos metálicos estão sujeitos à imobilização na biomassa microbiana e à mineralização. Essas transformações envolvem diversos processos bioquímicos microbianos. Apesar desses mecanismos serem bem delineados pouco se sabe sobre a capacidade da biomassa do solo em acumular metais. O que se tem registro é de que a capacidade de absorção e o acúmulo de metais nos tecidos microbianos é diferenciada.

Tabela 3- Resultados das análises físico-químicas com a quantificação de metais.

\begin{tabular}{l|c|c|c|c|c|c|c}
\hline Tipo de Solo & $\begin{array}{c}\mathrm{Zn} \\
\mathrm{mgL}^{-1}\end{array}$ & $\begin{array}{c}\mathrm{Cu} \\
\mathrm{mgL}^{-1}\end{array}$ & $\begin{array}{c}\mathrm{Mn} \\
\mathrm{mgL}^{-1}\end{array}$ & $\begin{array}{c}\mathrm{K} \\
\mathrm{mgL}^{-1}\end{array}$ & $\begin{array}{c}\mathrm{Mg} \\
\mathrm{cmlcL}^{-1}\end{array}$ & $\begin{array}{c}\mathrm{Al} \\
\mathrm{cmlcL}^{-1}\end{array}$ & \begin{tabular}{c}
$\mathrm{Ca}_{\mathrm{cmlcL}^{-1}}$ \\
\hline Floresta Nativa
\end{tabular} \\
\hline $\begin{array}{l}\text { Produção de } \\
\text { Pastagem }\end{array}$ & 68,3 & 0,4 & 65 & 501 & 5,3 & 0,0 & 32,3 \\
\hline $\begin{array}{l}\text { Plantação Agrícola } \\
\text { Temporária }\end{array}$ & 9,0 & 8,5 & 215 & 326 & 3,1 & 0,2 & 11,5 \\
\hline
\end{tabular}

Fonte: Autoras (2019).

Tabela 4- Resultados das análises físico-químicas com a quantificação de nãometais.

\begin{tabular}{l|c|c|c|c}
\hline Tipo de Solo & $\begin{array}{c}\text { P } \\
\mathrm{mgL}^{-1}\end{array}$ & $\begin{array}{c}\text { S } \\
\mathrm{mgL}^{-1}\end{array}$ & $\begin{array}{c}\mathrm{N} \\
\mathrm{mgL}^{-1}\end{array}$ & $\begin{array}{c}\text { B } \\
\mathrm{mgL}^{-1}\end{array}$ \\
\hline Floresta Nativa & 9,4 & 29,0 & 1,3 & 2,0 \\
\hline Produção de Pastagem & 64,3 & 25,0 & 1,3 & 0,6 \\
\hline $\begin{array}{l}\text { Plantação Agrícola Tem- } \\
\text { porária }\end{array}$ & 11,5 & 30,5 & 6,9 & 0,3 \\
\hline
\end{tabular}

Fonte: Autoras (2019). 
Tabela 5- Análise de biomassa microbiana (B.M.), respiração basal (R.B.) e quociente microbiano $\left(q \mathrm{Co}_{2}\right)$.

\begin{tabular}{l|c|c|c}
\hline Tipo de Solo & $\begin{array}{c}\text { B.M. } \\
(\mu \mathrm{g} / \mathrm{Kg})\end{array}$ & $\begin{array}{c}\text { R.B. } \\
(\mu \mathrm{g} \mathrm{CO} 2 / \mathrm{g} \\
\text { solo/hora })\end{array}$ & $\begin{array}{c}q \mathrm{Co}_{2} \\
q \mathrm{Co}_{2} \times 0^{-4}\end{array}$ \\
\hline Floresta Nativa & 754,4 & 0,96 & 12,0 \\
\hline Produção de Pastagem & 958,7 & 0,64 & 6,0 \\
\hline Plantação Agrícola Temporária & 497,9 & 1,01 & 8,0 \\
\hline
\end{tabular}

Fonte: Autoras (2019).

Os resultados das análises de biomassa microbiana (B.M.), respiração basal (R.B.) e quociente microbiano $\left(q \mathrm{Co}_{2}\right)$ estão na Tabela 5. A biomassa microbiana representa a fixação do carbono quando resíduos vegetais ficam na superfície. Sendo assim, áreas com maior circulação de gado tendem a ter maior desenvolvimento desta biomassa, pois ocorre a deposição de esterco e urina, acumulando carbono orgânico (HAYNES; WILLIAMS, 1999). Pastagens constituídas de gramíneas também podem apresentar grande conteúdo de biomassa microbiana na rizosfera, por serem um sistema denso e bem manejado (ALVARENGA et al., 1999).

Quanto à respiração basal, para Colozzi Filho et al. (2001), está relacionada ao resultado dos metabolismos da maioria dos microrganismos presentes no solo, tendo-se apresentado com uma determinação sensível, podendo assim, ser utilizada como indicador de qualidade do solo por meio dos diferentes tipos de manejos que os mesmos recebem. Com o presente estudo, tem-se a comprovação desta teoria, pois mediante resultados encontrados, percebe-se que a respiração basal é mais elevada em solos de plantação, o qual recebe sistemas de manejo com frequência.

Os tipos de manejo nos solos de plantação causam resultados benéficos para as plantas, sendo promissores na melhoria do desenvolvimento microbiano. Isto se deve à manutenção de resíduos vegetais acumulados no solo, que promovem o aumento das atividades dos microrganismos decompositores e produtores de nutrientes (VARGAS; SCHOLLES, 2000).

$\mathrm{O}$ quociente microbiano $\left(q \mathrm{CO}_{2}\right)$ está relacionado com a respiração (produção e liberação de $\mathrm{CO}_{2}$ pelo solo) por unidade de biomassa microbiana por um determinado tempo. Esta análise é de extrema importância, pois pode contribuir para a avaliação da qualidade do solo. Quocientes microbianos mais altos podem apresentar concentrações elevadas de metais pesados, indicando um maior consumo de energia (BALOTA et al., 1998).

A biomassa microbiana se torna mais eficiente na utilização de recursos do ecossistema a partir do momento em que menos carbono é perdido para a atmosfera na forma de $\mathrm{CO}_{2}$ pela respiração, possibilitando assim, maior 
incorporação deste à biomassa microbiana, resultando em menores valores de qCO2 (DIONÍSIO et al., 2016). Confirma-se assim, o resultado encontrado neste estudo, em que o maior valor de biomassa microbiana foi observado para o solo de pastagem, com $958,7 \mu \mathrm{g} / \mathrm{Kg}$, obtendo o menor valor para quociente microbiano, que foi de $6,0 \times 10^{-4} q \mathrm{Co}_{2}$.

Por meio das análises microbiológicas realizou-se a quantificação de fungos (UFC/g de solo) encontrados em cada tipo de solo. Os resultados encontram-se na Tabela 6.

Tabela 6- Quantificação dos fungos (UFC/g) por tipo de solo.

\begin{tabular}{l|c}
\hline Tipo de Solo & $\begin{array}{c}\text { Quantidade de fungos encontrados } \\
\text { (UFC/g de solo) }\end{array}$ \\
\hline Floresta nativa & $1,4 \times 10^{3}$ \\
\hline Produção de Pastagem & $3,7 \times 10^{3}$ \\
\hline Plantação Agrícola Temporária & $5,1 \times 10^{3}$ \\
\hline
\end{tabular}

Fonte: Autoras (2019).

Pode-se verificar que nas áreas de plantação agrícola temporária e de produção de pastagem a quantidade de fungos é maior que na área de floresta nativa. Um dos fatores que pode estar contribuindo para que isso ocorra é a adubação química e orgânica, visto que ela aumenta o desenvolvimento da comunidade biológica, devido ao aumento da disponibilidade de nutrientes (MOREIRA; SIQUEIRA, 2006).

Um estudo realizado por Prade et al. (2007), também na região do Vale do Taquari, avaliou os gêneros de fungos mais encontradas em solos de diferentes manejos em um pomar de Citrus, sendo elas Aspergillus, Fusarium, Alternaria, Pestalotiopsis, Bipolaris, Cladosporium, Verticillium, Curvularia e Penicillium. Por meio de uma análise comparativa, pode-se perceber que os gêneros encontrados em seus estudos são análogos aos encontrados na presente pesquisa (Tabela 7). 
Tabela 7- Gêneros de fungos encontrados nos diferentes tipos de solos amostrados.

\begin{tabular}{c|c|c|c|c}
\hline \multirow{2}{*}{ Gêneros de fungos } & \multicolumn{4}{|c}{ Tipos de solo } \\
\cline { 2 - 5 } & $\begin{array}{c}\text { Floresta } \\
\text { Nativa }\end{array}$ & $\begin{array}{c}\text { Produção de } \\
\text { Pastagem }\end{array}$ & $\begin{array}{c}\text { Plantação } \\
\text { Agrícola } \\
\text { Temporária }\end{array}$ & Total \\
\hline Aspergillus sp. & 5 & 6 & 3 & $\mathbf{1 4}$ \\
\hline Penicillium sp. & 1 & 1 & 3 & $\mathbf{5}$ \\
\hline Fusarium sp. & 2 & 2 & 1 & $\mathbf{5}$ \\
\hline Candida sp. & 0 & 1 & 0 & $\mathbf{1}$ \\
\hline Curvularia $s p$. & 1 & 2 & 0 & $\mathbf{3}$ \\
\hline Cladosporium $s p$. & 0 & 4 & 0 & $\mathbf{4}$ \\
\hline Total & $\mathbf{9}$ & $\mathbf{1 6}$ & $\mathbf{5}$ & $\mathbf{3 2}$ \\
\hline
\end{tabular}

Fonte: Autoras (2019).

Os gêneros de fungos Aspergillus e Penicillium, os quais são facilmente encontrados no solo, podem originar sintomas indesejáveis, tais como alergia, micoses e problemas respiratórios, tanto para o ser humano como para os animais. Os fungos destes gêneros tornam-se importantes por apresentarem benefícios para a economia, devido aos diversos atributos em seu conjunto de transformações e reações químicas por meio de sínteses de decomposição, podendo ser utilizados nas mais diversas pesquisas biotecnológicas (MONTEIRO, 2012).

Nos estudos de Carvalho (2008), o qual realizou uma análise entre monoculturas de soja e algodão e a vegetação nativa do Cerrado, o gênero Fusarium sp. foi o mais abundante, sendo encontrado mais frequentemente nas áreas de plantação agrícola temporária. O manejo utilizado para manutenção do solo pode influenciar a presença constante desse tipo de fungo, especialmente a manipulação de forma direta e semidireta. Estas formas de manutenção acumulam resíduos nas superfícies do solo, promovendo a sobrevivência desses agentes pelo acúmulo de matéria-orgânica.

Para o presente estudo, Fusarium sp. apresentou-se com maior evidência em solos de floresta nativa e para a produção de pastagem, áreas com bastante deposição de matéria-orgânica na superfície. O fungo de gênero Cladosporium $\mathrm{sp}$, apresenta condições de sobrevivência em solos com resíduos agrícolas (CARVALHO, 2008), sendo encontrado em solo de pastagem no presente estudo. Rossetto (2003) identificou o aumento da presença de Cladosporium sp. em solos com plantação de algodão após a aplicação de calcário, indicando que mudanças na manutenção do ambiente podem afetar positivamente o crescimento dessas espécies. 
Estudos de Angelini et al. (2012) sugerem que o manejo do solo influencia a comunidade fúngica presente no local. Seus testes definiram a densidade de esporos, as colonizações micorrízicas e a diversidade de fungos presentes neste local. Os resultados indicaram que solos preparados pelo manejo convencional apresentam menor diversidade fúngica quando comparados a solos de plantio direto, indicando a relação do uso do solo com as alterações na sua comunidade biológica.

Utilizando metodologia semelhante a aplicada neste estudo, Cavalcanti et al. (2006) isolaram fungos filamentosos de solos na região da caatinga, com solo coberto por vegetação rasteira e leguminosa. Os resultados mostraram como gênero mais abundante Penicillium, seguido de Aspergillus e Fusarium. Também foram encontrados os gêneros Curvularia e Cladosporium em menor número, semelhante aos resultados encontrados nesta pesquisa.

\section{CONCLUSÃO}

Os aspectos físico-químicos e biológicos de solos de diferentes tipos de manejo, em uma mesma área, estão relacionados ao comportamento de comunidades microbianas e que, dependendo da utilização deste solo, poderão variar em quantidades e diversidade biológica. O solo de plantação agrícola temporária foi o que apresentou maior quantidade e diversidade de fungos. Isto é possibilitado por este ser um ambiente com mais atividade humana, que causam modificações físico-químicas, biológicas e microbiológicas por meio da adição ou remoção de elementos que o compõem, e também pelas práticas de cultivo que esse tipo de solo recebeu durante anos de produção contínua, ocasionando o seu desgaste. Para o solo de floresta nativa, no qual não ocorrem manuseios indesejáveis da terra, tem-se uma quantidade maior de matériaorgânica e, consequentemente, maior quantidade de carbono presente nesta área pode ser observada a maior quantidade de biomassa microbiana $(958,7$ $\mu \mathrm{g} / \mathrm{Kg}) . \mathrm{O} \mathrm{pH}$ encontrado nas áreas amostradas, indica que o ambiente é propício para o desenvolvimento de fungos, bem como as baixas concentrações de zinco e manganês, cobre e fósforo.

Assim, frente aos resultados das análises físico-químicas e biológicas obtidos e a comparação desses dados com os demais estudos, pode-se perceber que as metodologias testadas podem ser utilizadas e implementadas no grupo de pesquisa.

\section{REFERÊNCIAS}

ALMEIDA D. et al. Carbono, nitrogênio e fósforo microbiano do solo sob diferentes coberturas em pomar de produção orgânica de maçã no sul do Brasil. Bragantia, Campinas, v.68, p.1069-1077, 2009. 
ALVARENGA M.I.N. et al. Teor de carbono, biomassa microbiana, agregação e micorriza em solos de Cerrado com diferentes usos. Ciência e Agrotecnologia Lavras, v. 23, n.3, p.617-625, 1999.

ALVES, F.G.S. et al. Considerações sobre manejo de pastagens na região semiárida do Brasil: Uma Revisão. Revista Brasileira de Higiene e Sanidade Animal, v.8, n.4, p.259-283, 2014.

ANDERSON, T.H.; DOMSCH, K.H. Application of eco-physiological quotients (qCO2 and qD) on microbial biomasses from soils of different cropping histories. Soil Biology and Biochemistry, v. 22, n. 2, p. 251-255, 1990.

ANDRADE, D.S. et al. Atividade microbiana em função da calagem em um solo cultivado com cafeeiro. Revista Brasileira de Ciência do Solo, v.19, p.191-196, 1995.

ANGELINI, G.A.R. et al. Colonização micorrízica, densidade de esporos e diversidade de fungos micorrízicos arbusculares em solo de Cerrado sob plantio direto e convencional. Semina: Ciências Agrárias, v.33, n.1, p.115-130, 2012.

BALOTA, E. L. et al. Biomassa microbiana e sua atividade em solos sob diferentes sistemas de preparo e sucessão de culturas. Revista Brasileira de Ciência do Solo, v. 22, p. 641-649, 1998.

BRADY, N.C. Natureza e Propriedades dos Solos / Nyle C. Brady "The nature and prieties of solis" Trad. Antônio B. Neiva Figueiredo Filho, 7 eds. Rio de Janeiro: Fretiras Bastos, 1989. 877 p.

BRADY, N.C., WEIL, R.R. Elementos da natureza e propriedades dos solos. 3 eds. Bookman Editora, 2012. 716 p.

CARVALHO, V.G. Comunidades de fungos em solo do cerrado sob vegetação nativa e sob cultivo de soja e algodão. 62 f. Dissertação (Mestrado em Microbiologia Agrícola) - Universidade Federal de Lavras, Lavras, 2008.

COLOZZI FILHO, A. et al. Atividade microbiana em solos cultivados em sistema plantio direto. Informação Agropecuária, Belo Horizonte, v. 22, n. 208, p. 84-91, 2001.

COELHO, M.R. et al. Solos: tipos, suas funções no ambiente, como se formam e sua relação com o crescimento das plantas. Cares, J.E.; Zanetti, R.; Stumer, S. L. O ecossistema o solo: componentes, relações ecológicas e efeitos na produção vegetal. Lavras, MG: UFLA, 2013.

CAVALCANTI, M.A. Q. et al. Fungos filamentosos isolados do solo em municípios na região Xingó, Brasil. Acta Botanica Brasilica, v.20, n.4, p.831-837, 2006.

DIONÍSIO J.A. et. al. Guia Prático de Biologia do Solo. Curitiba - Paraná: SBCS/ NEPAR, p. 80, 2016. 
DOMSCH, K.H.; WALTER; A. Traute-Heide. Compendium of soil fungi. London: Academic. p.672, 2007.

ELLIS, M.B. Dematiaceous hyphomycetes. Kew: Commonwealth Mycological Institute, p. 608, 1971.

EMBRAPA. Centro Nacional de Pesquisa de Solos (Rio de Janeiro, RJ). Sistema brasileiro de classificação de solos. 2 eds. Rio de Janeiro: EMBRAPA-SPI, 2006.

EMBRAPA. Centro Nacional de Pesquisa de Solos (Rio de Janeiro, RJ). Manual de métodos de análise de solo. 2 eds. rev. Atual. Rio de Janeiro, 1997.

FEIX, R.D. A aglomeração produtiva de laticínios do Vale do Taquari. In: Macadar, Porto Alegre: FEE, p. 521-564, 2016.

FEE- Fundação de Economia e Estatística (2015). Disponível em: <http:/ / www.fee. rs.gov.br/perfil-socioeconomico / coredes / detalhe $/$ ?corede=Vale+do+Taquari $>$ Acesso em: abril de 2017.

GRISI, B.M.; GRAY, T.R.G. Comparação dos métodos de fumigação, taxa de respiração em resposta à adição de glicose e conteúdo de ATP para estimar a biomassa microbiana do solo. Revista Brasileira de Ciência do Solo, v.10, p.109-115, 1986.

HAYNES, R.J.; WILLIAMS, P.H. Influence of stock camping behavior on the soil microbiological and biochemical properties of grazed pastoral soils. Biology and Fertility of Soils, v. 28, p.253- 258, 1999.

IBGE - Instituto Brasileiro Geografia Estatística. Produção da Pecuária Municipal — 2016. Rio de Janeiro: IBGE, 2017.

JUNG, C. F.; JUNIOR, A. M. Produção leiteira no Brasil e características da bovinocultura leiteira no Rio Grande do Sul. Revista de História e Geografia Ágora. Universidade de Santa Cruz do Sul - UNISC, Santa Cruz do Sul, v.19, n. 1, p. 34-47, jan./jun. 2017.

KITAMURA A.E. et. al. Relação entre a variabilidade espacial das frações granulométricas do solo e a produtividade do feijoeiro sob plantio direto. Revista Brasileira de Ciência do Solo, v.31 n. 2, p. 361-369, 2007.

KIEHL, E.J. Manual de edafologia: relações solos - planta. São Paulo: Agronômica Ceres, p.262, 1979.

LONGO, R. M.; SPINDOLA, C.R. C-orgânico, N-total e substâncias húmicas sob influência da introdução de pastagens (Brachiaria sp.) em áreas de cerrado e floresta amazônica. Revista Brasileira de Ciência do Solo, v. 24, p.723-729, 2000.

MARCHIORI JÚNIOR, M.;MELO, W.J.D. Alterações na matéria orgânica e na biomassa microbiana em solo de mata natural submetido a diferentes manejos.

Pesquisa Agropecuária Brasileira, v.35, n.6, p.1177-1192, 2000. 
MONTEIRO, M.C.P. Identificação de fungos dos gêneros Aspergillus e Penicillium em solos preservados do cerrado, 2012.

MOREIRA, F.M.S.; SIQUEIRA, J.O. Microbiologia e Bioquímica do Solo, Editora UFLA, 2006.

PES, L.Z., ARENHARDT, M. H. Solos. Colégio Politécnico UFSM: Santa Maria, 2015. 90 p.

PRADE, C.A. et al. Diversidade de fungos do solo em sistemas agroflorestais de Citrus com diferentes tipos de manejo no município de Roca Sales, Rio Grande do Sul. Biociências, v.15, n.1, p.73-81, 2007.

PITT, J.I., HOCKING, A.L. Fungi and Food Spoilage. 3th ed. New York: Springer, 2009.

ROSSETTO, C.A.V. et al. Efeito da calagem, da colheita e da secagem na qualidade sanitária de amendoim na seca. Pesquisa Agropecuária Brasileira, v.15, n.5, p.567$573,2003$.

SANTOS, B.R.C. et. al. Correlação do fósforo no sistema solo-planta-animal em pastagem natural na região da Campanha-RS. Revista Brasileira de Ciência do Solo, v.3, n.1, p.26-33, 2009.

SETZER, J. As características dos principais tipos de solos do estado de São Paulo. Bragantia, v.1, n.4, 1941.

SILVA, A.J.N. et al. Alterações físicas e químicas de um Argissolo amarelo sob diferentes sistemas de uso e manejo. Revista Brasileira de Engenharia Agrícola e Ambiental, v.10, n.1, p.76-83, 2006.

SILVA, D. A.; POLLI, H. Q. A importância da agricultura orgânica para a saúde e meio ambiente. Interface Tecnológica, v. 10, n. 1, p. 505-516, 2020.

SILVA, L.G. et al. Atributos físicos, químicos e biológicos de um Latossolo de Cerrado em plantio de espécies florestais. Pesquisa Agropecuária Brasileira, v.44, p.613-620, 2009.

STOTZKY, G. Microbial respiration. In: Methods of soil analysis, Madison: American Society of Agronomy, v. 2, n. 1, p. 1551-1572, 1965.

TORTORA, G.J.; FUNKE, B.R.; CASE, C.L. Microbiologia. 12. ed. Porto Alegre: Artmed, 2016. 964p.

VANCE, E. D.; BROOKES, P. C.; JENKINSON, D. S. Na extraction method for measuring soil microbial biomass C. Soil Biology Biochemistry, v.19, n.6 p.703-707, 1987.

VARGAS, L. K.; SCHOLLES, D. Biomassa microbiana e produção de C-CO2 e N mineral de um Podzólico Vermelho Escuro submetido a diferentes sistemas de manejo. Revista Brasileira de Ciência do Solo, v. 24, n. 1, p. 35-42, 2000. 